\title{
Linfoma plasmablástico oral en un paciente pediátrico con virus de inmunodeficiencia humana/síndrome de inmunodeficiencia adquirida: a propósito de un caso
} Oral plasmablastic lymphoma in a human immunodeficiency virus positive child: a case report

\author{
Méd. María F. Astolfo, Méd. Federico D'Antonio , Méd. Juan B. Dartiguelongue ${ }^{b}$, Méd. María N. Arabolaza , \\ Méd. Ariel Cheistwer ${ }^{b}$, Méd. Elena De Matteo ${ }^{c}$, Méd. Lidia Torrado y Méd. Emilio Martínez Iriart ${ }^{b}$
}

\section{RESUMEN}

El linfoma plasmablástico es un subtipo raro y agresivo de linfoma no Hodgkin de células grandes B, descrito inicialmente en la cavidad oral de adultos varones con enfermedad por virus deinmunodeficienciahumana/síndromedeinmunodeficiencia adquirida. Se compone de una proliferación de células neoplásicas que se asemejan a losinmunoblastos, pero presentan inmunofenotipo característico de célula plasmática e infección latente por el virus de Epstein-Barr. En la población pediátrica, es una entidad excepcional.

Presentamos el caso de una niña de 5 años de edad, con enfermedad por virus de inmunodeficiencia humana/síndrome de inmunodeficiencia adquirida de transmisión vertical con linfoma plasmablástico de cavidad oral.

Palabras clave: linfoma plasmablástico, virus de Epstein-Barr, pediatría, infecciones por virus de inmunodeficiencia humana.

\begin{abstract}
Plasmablastic lymphoma is a rare and aggressive subtype of diffuse large B cell non-Hodgkin lymphoma, originally described in the oral cavity of male adults with acquired immune deficiency syndrome. It is composed of neoplastic cells which resemble immunoblasts but present immunophenotype distinctive of plasma cell and Epstein-Barr virus latent infection. In children, it is an even rarer disease.

We present a case of oral plasmablastic lymphoma in a vertically transmitted human immunodeficiency virus-positive fiveyear-old child.

Key words: plasmablastic lymphoma, Epstein-Barrvirus, pediatrics, human immunodeficiency virus infection.
\end{abstract}

http:/ /dx.doi.org/10.5546/aap.2016.e95

\section{INTRODUCCIÓN}

El linfoma plasmablástico (plasmablastic lymphoma; PBL, por sus siglas en inglés) es una proliferación clonal maligna clasificada por la Organización Mundial de la Salud como un subtipo de linfoma no Hodgkin de células grandes B. ${ }^{1}$ Desde su descripción inicial en pacientes adultos con virus de inmunodeficiencia humana (VIH)/ síndrome de inmunodeficiencia adquirida (SIDA) como un tumor que afectaba preferentemente la cavidad oral, se han reportado varios casos en pacientes inmunocomprometidos por otras causas, con localización fuera de la cavidad oral, tanto ganglionar como extraganglionar. ${ }^{2}$

Debido a sus características morfológicas, inmunohistoquímicas y a su curso clínico agresivo y de rápido crecimiento, representa un verdadero desafío diagnóstico y terapéutico. Por lo general, se diagnostica en estadios clínicos avanzados y, a pesar de presentar una respuesta inicial favorable a la quimioterapia, la tasa de recaídas es alta y el pronóstico desfavorable. ${ }^{3}$

\section{CASO CLÍNICO}

Paciente de sexo femenino de 5 años de edad con VIH/SIDA estadio C3 de transmisión vertical. Fue diagnosticada a los 6 meses de vida y presentaba mala adherencia al tratamiento antirretroviral de alta eficacia (HAART por sus siglas en inglés), que consistía en zidovudina, lamivudina y lopinavir/ritonavir. Ambos padres de la paciente habían fallecido. Consultó por presentar una tumoración en la región maxilar superior izquierda de 15 días de evolución, no dolorosa, afebril.

Al momento del ingreso se la evaluó crónicamente enferma, hemodinámicamente 
estable, con una tumoración maxilar que comprometía la región gingival superior izquierda, cubierta por mucosa eritematosa, de consistencia duroelástica, no fluctuante e indolora, de alrededor de $5 \times 7 \mathrm{~cm}$, que provocaba una sustancial deformación facial (Figura 1). Se realizó una tomografía computarizada de macizo facial, en la que se observó una imagen con densidad de partes blandas, en contacto íntimo con el borde anterior del maxilar superior y el ala izquierda de la nariz, que provocaba una erosión de la cortical ósea del maxilar superior, de aproximadamente $2,5 \times 3 \times 1 \mathrm{~cm}$ de diámetro, con ligero refuerzo con el contraste endovenoso (Figura 2). Se realizaron tomografías del sistema nervioso, del tórax y del abdomen, que resultaron normales.

El hemograma de ingreso evidenció plaquetopenia $\left(61000 / \mathrm{mm}^{3}\right)$ como único hallazgo patológico. El coagulograma, la función renal y hepática, la lactato deshidrogenasa (LDH) y la proteína $\mathrm{C}$ reactiva fueron normales. El recuento de linfocitos $\mathrm{CD}^{+}$fue de $244 \mathrm{cel} . / \mathrm{mm}^{3}$ y la carga viral, de 340000 copias $/ \mathrm{mL}(\log 5,53)$. Se tomó una biopsia incisional de la lesión, que mostró infiltración submucosa difusa por células neoplásicas de núcleos redondos, con cromatina grumosa y escaso citoplasma, alto índice mitótico y áreas de necrosis (Figura 3). Se realizó la técnica de inmunohistoquímica y se halló positividad intensa y difusa con CD45 (antígeno común

FIgURA 1. Fotografía de la paciente, que muestra tumoración facial en la zona maxilar izquierda

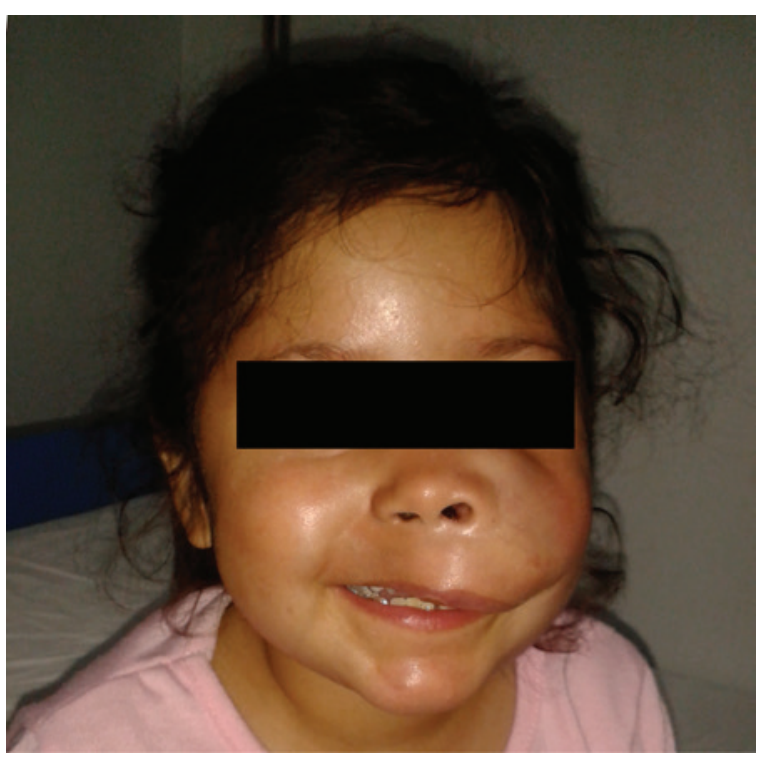

leucocitario), positividad focal con vimentina y un índice de proliferación con Ki67 del 100\%. Las células tumorales fueron negativas con CD20, CD3, CD30 y citoqueratina. Con estos hallazgos, se realizó el diagnóstico preliminar de linfoma de células B no Burkitt.

FIgURA 2. Tomografía computarizada del macizo facial, que muestra la lesión descrita. Esta provoca ligera erosión de la cortical ósea del maxilar superior izquierdo (flecha)
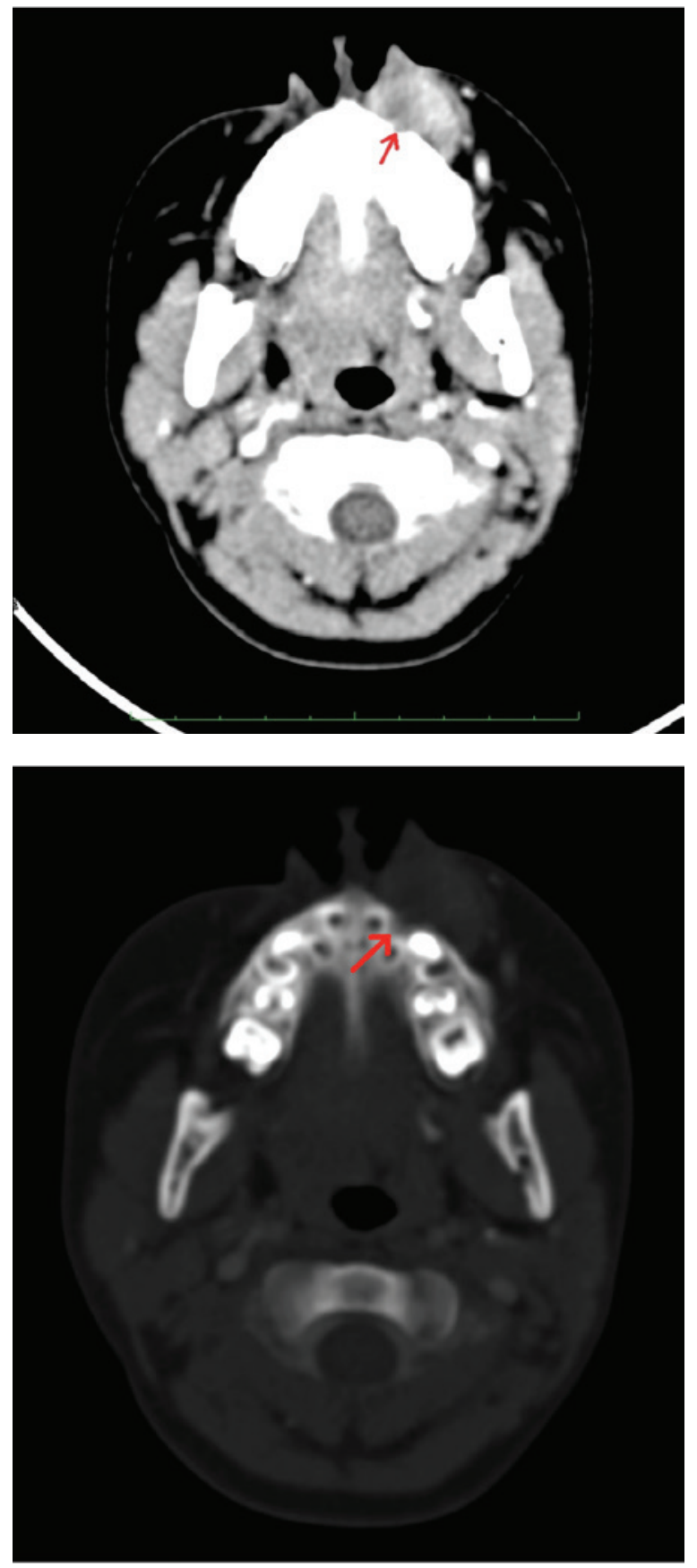
Por el rápido crecimiento tumoral, inició quimioterapia de prefase con dexametasona y ciclofosfamida. Se amplió el panel de inmunomarcación y se halló positividad con CD138 (antígeno asociado a célula plasmática) y MUM1 (oncogen 1 de mieloma múltiple), por lo que se diagnosticó linfoma plasmablástico (Figura 4). La hibridación in situ para ARN mensajero de virus de Epstein-Barr (EBER ISH por sus siglas en inglés) fue positiva. Para completar la estadificación se realizaron punción y biopsia de médula ósea (normales) y punción lumbar con presencia de células neoplásicas (estadio IV). Comenzó quimioterapia de inducción con vincristina, dexametasona, etopósido y citarabina, asociada a tratamiento intratecal con dexametasona, metotrexato y citarabina.

A pesar de haber presentado una marcada disminución del tamaño de la lesión con el tratamiento citostático, la paciente falleció por shock séptico por Acinetobacter a las 2 semanas de haberse realizado el diagnóstico.

Se ha obtenido autorización del Comité de Ética del Hospital de Niños "Dr. Ricardo Gutiérrez" para la publicación de este caso clínico.

\section{DISCUSIÓN}

El linfoma no Hodgkin representa el 65\% de las enfermedades malignas en niños con VIH. El PBL es un subtipo raro de linfoma no Hodgkin, originalmente descrito como una variante de linfoma de células grandes $B$, con fuerte asociación a infección latente por el EBV. Si

FiguRA 3. Biopsia maxilar; coloración con hematoxilina y eosina (400x). Se observa una proliferación de células medianas con rasgos plasmocitoides y marcada apoptosis

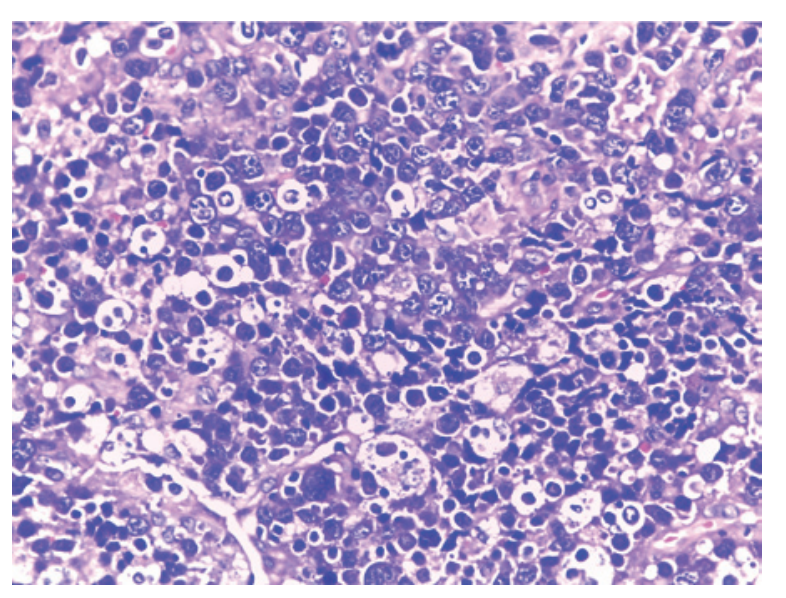

bien es más frecuente en adultos varones, el rango etario en que se presenta es amplio. ${ }^{1,2}$

En general, las localizaciones más comunes del PBL son las extraganglionares. En pacientes con VIH, la cavidad oral/nasal es el sitio principal de compromiso. En receptores de trasplante de órgano sólido, la piel es una localización frecuente. ${ }^{4}$ Otros sitios de compromiso primario extraorales frecuentes son el tracto gastrointestinal y los ganglios linfáticos. La localización ganglionar se observa con mayor frecuencia en pacientes VIH negativos. ${ }^{1,3}$

Aunque su curso clínico es muy agresivo y la supervivencia es, en general, menor a un año, se han reportado pacientes con seguimiento a largo plazo libres de enfermedad. ${ }^{4}$

El PBL representa un desafío diagnóstico, ya que otras entidades pueden presentarse con

Figura 4. Microfotografía de la lesión, con técnica de inmunohistoquímica positiva: A) para CD138 (40x); B) para MUM1 (400x)

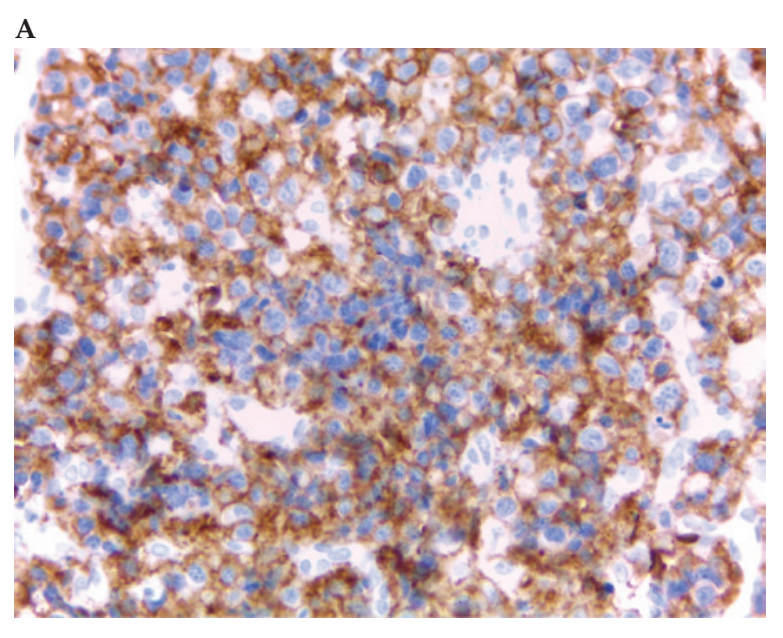

B

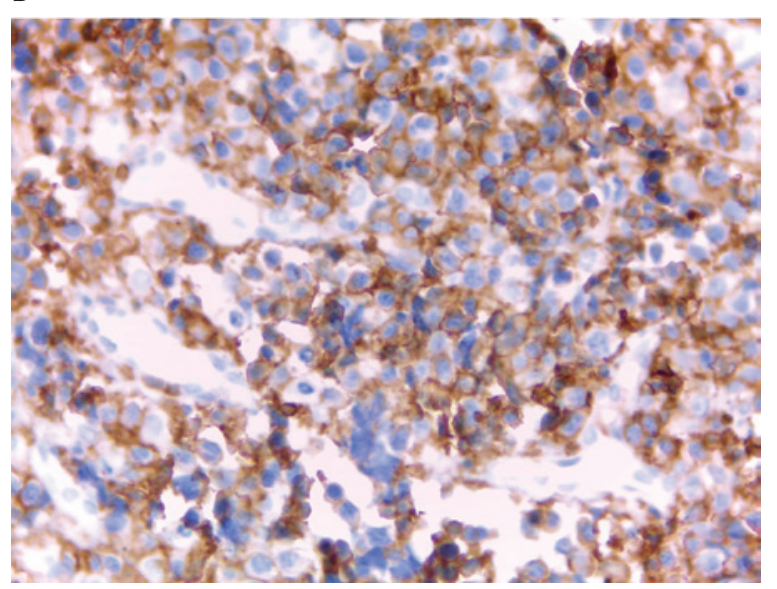


histología y fenotipo similar, lo que implica la presencia de células blásticas grandes con escasa o ausente expresión de marcadores de linfocitos B (CD20) y con positividad para antígenos relacionados con plasmocitos (CD138 y MUM1). ${ }^{5}$

Dentro del grupo de los linfomas de células grandes $\mathrm{B}$ con diferenciación plasmoblástica, se describen dos subtipos principales: el $P B L$ con diferenciación plasmocítica y el PBL de tipo mucosa oral. Ambos difieren en características clínicas, epidemiológicas, morfológicas e inmunofenotípicas, aunque con cierta superposición.

El PBL con diferenciación plasmocítica se puede presentar como una enfermedad ganglionar o extraganglionar. Se observa principalmente en pacientes inmunosuprimidos por causas distintas al VIH.

Al igual que el PBL de tipo mucosa oral, esta variante está relacionada con infección latente por EBV y su pronóstico es ominoso. Histológicamente, está compuesto por una población heterogénea de plasmoblastos e inmunoblastos, como también por células pequeñas con diferenciación plasmocítica, con una expresión variable de restricción de cadenas livianas de inmunoglobulinas.

El PBL de tipo mucosa oral tiene predilección por la cavidad oral, el área nasal o paranasal y se asocia fuertemente a VIH/SIDA. Puede presentarse también en pacientes con inmunosupresión secundaria a corticoterapia prolongada o trasplante de órganos sólidos y en la población anciana. Una pequeña proporción de pacientes presenta PBL secundario a la progresión de otra enfermedad hematológica, principalmente, leucemia linfática crónica y linfoma folicular. La EBER ISH es positiva en el $75 \%$ de los casos de PBL relacionados con VIH/ SIDA. ${ }^{1,3,4}$ Desde el punto de vista histológico, se observa una población relativamente homogénea de células linfoides grandes con características inmunoblásticas, figuras mitóticas frecuentes y un índice alto de Ki-67. A pesar de una respuesta inicial favorable, su curso clínico está caracterizado por un índice alto de recaídas y muerte. ${ }^{5}$

Entre los diagnósticos diferenciales del PBL, se incluyen distintos tumores sólidos (carcinoma, rabdomiosarcoma, osteosarcoma) y procesos linfoproliferativos con diferenciación plasmoblástica: mieloma plasmablástico, linfoma difuso de células B grandes con diferenciación plasmocitoide, linfoma anaplásico kinasa positivo (ALK+), linfoma primario de cavidades positivo para virus herpes 8 (human herpesvirus-8; HHV-8, por sus siglas en inglés) y el linfoma HHV-8+ asociado a la enfermedad de Castleman multicéntrica. La presencia de infección latente por el EBV, la ausencia de infección por HHV-8, la asociación a VIH, la presentación extraganglionar, la ausencia de gammapatía monoclonal, la negatividad para CD20 y otros marcadores de células B, así como un inmunofenotipo característico de célula plasmática, son las claves para diferenciar el PBL de otras enfermedades oncohematológicas. ${ }^{3}$

El PBL es extremadamente infrecuente en niños. De los pacientes publicados a la fecha, 6 corresponden a reportes de casos. ${ }^{6-11} \mathrm{Se}$ describen, además, tres series de casos que incluyen pacientes pediátricos y adultos, ${ }^{4,5,12}$ y dos series de casos de PBL en pediatría. ${ }^{13,14}$ Aunque el pronóstico es, por lo general, desfavorable, del total de los 25 pacientes publicados, 8 se encontraban vivos al momento del último seguimiento. ${ }^{4,8,11-14}$

El reconocimiento de la enfermedad ha ido aumentando en los últimos años. Esto probablemente se deba a una mayor sospecha de la entidad y a la búsqueda retrospectiva de pacientes con cuadros compatibles en bases de datos de anatomía patológica.

En pediatría no existe un tratamiento estandarizado debido a la escasez de datos. En adultos, se ha utilizado por varios años como primera línea terapéutica ciclofosfamida, doxorrubicina, vincristina y prednisolona (CHOP). Actualmente el CHOP se considera inadecuado y se proponen, tanto para pacientes VIH positivos como negativos, esquemas terapéuticos más agresivos, como etopósido, prednisona, vincristina, ciclofosfamida y doxorrubicina $(\mathrm{EPOCH})$, aunque no existe evidencia de que ellos puedan ofrecer mejor supervivencia. En pacientes con VIH/SIDA, se aconseja el uso de profilaxis intratecal. ${ }^{3,15} \mathrm{En}$ la paciente que presentamos, se optó por un esquema citostático para linfoma no Hodgkin de alto grado similar al CHOP con el agregado de citarabina y tratamiento intratecal.

Se ha propuesto además el uso de nuevos agentes antimieloma, como bortezomib, así como el trasplante autólogo de médula ósea en la primera remisión de pacientes con enfermedad quimiosensible. $^{3}$

A pesar de la potencialidad de interacciones con el tratamiento citostático, se sugiere 
comenzar o continuar con el HAART. ${ }^{15}$ No se conoce, sin embargo, en qué medida el tratamiento antirretroviral puede ofrecer un pronóstico más favorable.

\section{CONCLUSIONES}

Aunque el PBL es una enfermedad excepcional en pediatría, se lo debe sospechar frente a la aparición de un tumor de rápido crecimiento en la zona oral-nasal en un paciente con VIH/SIDA.

La falta de datos prospectivos dificulta el establecimiento de un tratamiento estandarizado.

Como ocurre en el adulto, sus características morfológicas e inmunofenotípicas, su curso clínico agresivo y su pronóstico desfavorable hacen de su diagnóstico y tratamiento un desafío continuo.

\section{REFERENCIAS}

1. Stein H, Harris NL, Campo E. Plasmablastic lymphoma. En: Swerdlow SH, Campo E, Harris NL, Jaffe ES, et al, eds. WHO classification of tumours of haematopoietic and lymphoid tissues. $4^{\text {th }}$ ed. Lyon: IARC; 2008.Págs.256-7.

2. Delecluse HJ, Anagnostopoulos I, Dallenbach F, Hummel M, et al. Plasmablastic lymphomas of the oral cavity: a new entity associated with the human immunodeficiency virus infection. Blood 1997;89(4):1413-20.

3. CastilloJJ, Bibas M, Miranda RN. The biology and treatment of plasmablastic lymphoma. Blood 2015;125(15):2323-30.

4. Morscio J, Dierickx D, Nijs J, Verhoef G, et al. Clinicopathologic comparison of plasmablastic lymphoma in HIV-positive, immunocompetent, and posttransplant patients: single-center series of 25 cases and meta-analysis of 277 reported cases. Am J Surg Pathol 2014;38(7):875-86.
5. Colomo L, Loong F, Rives S, Pittaluga S, et al. Diffuse large B-cell lymphomas with plasmablastic differentiation represent a heterogeneous group of disease entities. Am J Surg Pathol 2004;28(6):736-47.

6. Radhakrishnan R, Suhas S, Kumar RV, Krishnanand G, et al. Plasmablastic lymphoma of the oral cavity in an HIVpositive child. Oral Surg Oral Med Oral Pathol Oral Radiol Endod 2005;100(6):725-31.

7. ApichaiS, Rogalska A, Tzvetanov I, AsmaZ, etal. Multifocal cutaneous and systemic plasmablastic lymphoma in an infant with combined living donor small bowel and liver transplant. Pediatr Transplant 2009;13(5):628-31.

8. Chabay P, De Matteo E, Lorenzetti M, Gutierrez M, et al. Vulvar plasmablastic lymphoma in a HIV-positive child: a novel extraoral localisation. J Clin Pathol 2009;62(7):644-6.

9. Hernández C,Cetner AS, Wiley EL. Cutaneous presentation of plasmablastic post-transplant lymphoproliferative disorderina 14-month old. Pediatr Dermatol 2009;26(6):713-6.

10. Gogia A, Bakhshi S. Plasmablastic lymphoma of oral cavity in a HIV-negative child. Pediatr Blood Cancer 2010;55(2):390-1.

11. Sharma A, TilakTV, Lodha R, Sharma MC, et al. Long-term survivor of human immunodeficiency virus-associated plasmablastic lymphoma. Indian J Med Paediatr Oncol 2013;34(2):96-8.

12. Kim JE, Kim YA, Kim WY, Kim CW, et al. Human immunodeficiency virus-negative plasmablasticlymphoma in Korea. Leuk Lymphoma 2009;50(4):582-7.

13. Pather S, MacKinnon D, Padayachee RS. Plasmablastic lymphoma in pediatric patients: clinicopathologic study of three cases. Ann Diagn Pathol 2013;17(1):80-4.

14. Vaubell JI, Sing Y, Ramburan A, Sewram V, et al. Pediatric plasmablastic lymphoma: a clinicopathologic study. Int $J$ Surg Pathol 2014;22(7):607-16.

15. National Comprehensive Cancer Network. NCCN Clinical Practice Guidelines in Oncology. Non-Hondkin's Lymphoma Versión 4.2014. Fort Washington, PA: NCCN; 2014. [Acceso: 17 de febrero de 2015]. Disponibleen: http:/ / www.nccn.org/about/nhl.pdf. 